\title{
Narrando alternativas: la historia y el discurso democrático en el pensamiento marroquí contemporáneo $(1997-2017)^{1}$
}

\author{
Narrating alternatives: story and democratic discourse in contemporary Moroccan thought \\ $(1997-2017)^{2}$
}

Juan A. MACÍAS AMORETTI

Universidad de Granada ${ }^{3}$

jamacias@ugr.es

https://orcid.org/0000-0002-8953-3705

Recibido 7/9/2018. Revisado y aceptado para publicación 3/12/2018

Para citar este artículo: Juan A. MACÍAS AMORETTI (2018), "Narrando alternativas: la historia y eldiscurso democrático en el pensamiento marroquí contemporáneo (1997-2017)" en Revista de Estudios Internacionales Mediterráneos, 25, 12-31.

Para acceder a este artículo: https://doi.org/10.15366/reim2018.25.002

\section{Resumen}

El presente artículo enfoca el parámetro narrativo en relación con la construcción ideológica del discurso democrático en Marruecos entre los años 1997 y 2017. Dicho análisis se fundamenta en la teoría estructuralista de S. Chatman para el análisis narrativo y lo aplica a la deconstrucción de la narrativa ideológica en dos elementos principales: la historia como elemento objetivable y el discurso como subjetividad. Estos elementos son analizados críticamente, siguiendo la metodología del Análisis Crítico del Discurso (ACD) de T. Van Dijk en el discurso de algunos de los pensadores de referencia en Marruecos: Kamāl 'Abd al-Latif, Ṭāhā 'Abd al-Raḥmān (n. 1944) y Muḥammad 'Ābid al-Ŷābrī (1935-2010).

\footnotetext{
${ }^{1}$ El presente trabajo se enmarca en el proyecto de I+D Ideología, texto y discurso: narrativas del cambio social en el Norte de África-IDENAF (Ref. FFI-2016-76307-R) financiado por el Plan Nacional de Investigación, Ministerio de Economía y Competitividad y los fondos FEDER de la Unión Europea, cuyo Investigador Principal es el autor. http://idenaf.hypotheses.org.

${ }^{2}$ This contribution is part of the research project 'Ideology, text and discourse: narratives of social change in North Africa-IDENAF' (Ref. FFI2016-76307-R) funded by the Spanish Ministry of Economy and the European FEDER funds, whose Principal Investigator is the author. http://idenaf.hypotheses.org.

${ }^{3}$ Investigador Visitante en el Middle East Centre-St. Antony's College de la Universidad de Oxford (Reino Unido) en el marco del Programa de movilidad 'José Castillejo' del Ministerio de Educación, Cultura y Deporte entre el 1 junio y el 30 de septiembre de 2018.
} 
Palabras clave: Pensamiento Político / Narrativa / Democracia / Discurso / Marruecos

\begin{abstract}
This article focuses on the narrative parameter and its relationship with the ideological construction of the discourse on democracy in Morocco between 1997 and 2017. The analysis uses S. Chatman's structuralist theory to deconstruct the ideological narrative into two main elements: story and discourse, the former as the objective element and the latter as subjectivity. Following the CDA methodology proposed by T. Van Dijk, both story and discourse are analysed critically in relation to three important contemporary Moroccan thinkers: Kamal 'Abd al-Latif, Ṭāhā 'Abd al-Raḥmān (b. 1944) and Muḥammad 'Ābid al-Ŷābrī (1935-2010).
\end{abstract}

Keywords: Political thought / Narrative / Democracy / Discourse / Morocco

\title{
Introducción: la narrativa democrática en Marruecos y el Análisis Crítico del Discurso
}

Tomado como base del marco teórico el análisis estructuralista de la narrativa desarrollado por S. Chatman (Chatman, 1978) y G. Genette (Genette, 1983), este trabajo pretende establecer una aproximación crítica e interdisciplinar al mismo desde una metodología cualitativa basada en el Análisis Crítico del Discurso (ACD) propuesto por T. Van Dijk (Van Dijk, 2016). Así, se toman como referentes fundamentales los conceptos estructurales que conforman toda narrativa, a saber, historia y discurso, si bien se aplican, en este caso, no a una narrativa artística como la novela o el cine, sino a una narrativa intelectual post-colonial, como es el caso de la narrativa democrática en Marruecos elaborada por algunos de los pensadores más destacados e influyentes de las últimas décadas, tanto dentro como fuera de Marruecos. Las posibilidades que ofrece este marco teórico narratológico, según el análisis de partida, contribuyen a clarificar las relaciones entre el elemento objetivable de la narrativa (la historia) y el elemento subjetivo (el discurso), inevitablemente mediado por el marco ideológico, es decir, histórico-político (praxis), cultural e identitario (antropológico).

El núcleo de esta narrativa de no-ficción está marcado por la concurrencia de hechos pertenecientes a la historia política "real" que son contemporáneos del discurso intelectual. La diferencia estriba en que en este caso, historia y discurso no son indisociables al no proceder de un mismo acto creativo. No obstante, puede afirmarse con G. Genette que no existe la "noficción" pura, aunque evidentemente el sentido de ambas es diferente (Genette, 1983:10). Así, frente a la narratología "temática" centrada en la historia, el presente análisis se inscribe de manera consciente en el análisis del discurso como modo de representación de la historia (Genette, 1983:12), en el que también tiene lugar el análisis ideológico de los conceptos, pues la significación de los mismos, siguiendo en este punto a T. Todorov, "no surge de la misma forma en la lengua y en el discurso, en las frases y en los enunciados, sino que toma formas netamente diferentes, hasta tal punto diferentes que merecerían nombres distintos" (Todorov, 1978:9). La construcción de una narración, en todo su sentido, supone en todo caso una toma de postura activa hacia el hecho mismo de contar, de narrar una determinada historia mediante un discurso (Genette, 1983:15). De esta manera es posible rastrear el discurso democrático elaborado desde la 
intelectualidad marroquí y contextualizarlo dentro de un proceso de retroalimentación mutua entre historia y discurso lo que, en otro nivel, se corresponde con la retroalimentación entre los propios intelectuales y la sociedad a la que pertenecen.

Así, el concepto de historia se presenta como un apriorismo objetivo, si bien debe ser analizado cuidadosamente desde la teorización de la historia post-colonial, a la que se hará mención a través de la crítica post-colonial y post-orientalista de H. Dabashi (Dabashi, 2009, 2012). En este sentido, el eje histórico objetivo estaría configurado por la ampliación limitada, interrumpida y (dis)continua (Macías Amoretti y Arigita, 2015) de los espacios democráticos en el espectro político y, sobre todo, social del Marruecos contemporáneo a lo largo de las últimas dos décadas, aproximadamente, en las que el cambio social, el empoderamiento de la sociedad civil (Pérez Beltrán, 2006), la democratización política (Parejo Fernández, 2010) y la autoconciencia cívicopolítica de la sociedad marroquí ha contribuido a aumentar su capacidad de interacción e interlocución social y política, es decir, su capacidad de acción transformadora (Vairel, 2014), como se ha puesto de manifiesto en numerosas ocasiones, tales como la puesta en marcha de los planes de igualdad de la mujer (2000) (Pérez Beltrán y Macías Amoretti, 2017), el proceso de reforma de la Mudawwana (2004), las protestas sociales de diferentes colectivos y movimientos sociales (desde los titulados en paro hasta los islamistas a lo largo de la década del 2000) (Buehler, 2018:64-68; Cavatorta y Merone, 2018:22-24), así como el proceso de protestas sociales que comienza con las manifestaciones del 20 de febrero de 2011 (Vairel, 2014:303-327), se prolonga hasta las protestas del Rif (hirāk al-Rîf, 2016-2017) y llega hasta el boicot ciudadano a determinados productos (2018) (Berrada e Iraqi, 2018). A ello, en este mismo proceso histórico discontinuo, se ha opuesto de manera constante el sistema de relaciones de poder vigente, que ha tenido que optar por determinadas reformas políticas puntuales (Maghraoui, 2013) y cambios estratégicos de discurso (Parejo Fernández, 2007) para mantener el statu quo post-colonial en la configuración del papel de las élites políticas y sociales en el marco del Estado (Izquierdo Brichs, 2012). En este proceso de reformas, los actores políticos tradicionales han tenido que reconfigurar su estrategia, bien adaptándose a los nuevos cambios o bien conformando alternativas, como es el caso de partidos como el Ḥizb al-'Adāla wa-I-Tanmiyya (Partido de la Justicia y el Desarrollo, PJD) o el Ḥizb al-'Așāla wa-I-Mu'āșara (Partido de la Autenticidad y la Modernidad, PAM), siempre en relación con el majzén, por una parte, y con la sociedad, por otra. Otros actores sociales, tales como organizaciones no gubernamentales, asociaciones de derechos humanos, sindicatos, etc. han elaborado su propio discurso en relación con la historia de los cambios sociales y la democratización en ámbitos como la reparación y la justicia ${ }^{4}$ (Loudiy, 2014: 10), en el que es reconocible la influencia de la narrativa democrática elaborada por los pensadores marroquíes más representativos a lo largo de los últimos veinte años. Todos estos elementos conforman la historia que es narrada por los intelectuales en su discurso, que se inscribe en una dinámica de cambio social contextualizada en el Magreb y en el resto del mundo árabe ('Abd al-'Ālī, 2013:15).

El discurso, por su parte, se entiende como la forma en la que los pensadores entienden, dialogan, expresan y narran dicho proceso histórico. En el cómo del discurso es donde cobran sentido los conceptos en torno a los que se genera el discurso democrático (democracia, sociedad civil, reforma, modernidad, cultura, turāt ) y aquéllos en torno a los que se genera el significado último del discurso y que, generalmente, se presentan como opuestos a los anteriores, o bien aparecen implícitamente (autoritarismo, corrupción, tradición, colonialialidad, neocolonialismo). La relación

\footnotetext{
${ }^{4}$ Tanto Loudy como Darif afirman la centralidad de las conclusiones de la Instancia Equidad y Reconciliación (2004) en el proceso democratizador de Marruecos (Loudy, 2014:10; Darif, 2014:108). Otros autores son más escépticos en este sentido, cuestionando el papel político y el alcance limitado de las propuestas de la IER (Vairel, 2014: 277-301).
} 
entre los conceptos generadores de discurso y los conceptos generadores de significado, siguiendo la terminología de Chatman y la metodología de Van Dijk, deben ser analizados teniendo en cuenta su naturaleza dialéctica e ideológica. Así, el análisis crítico del discurso propuesto por Van Dijk es entendido como una forma de "investigación disidente" (Van Dijk 2016:104) que considera el discurso como una manifestación textual del contexto ideológico, el cual enmarca y define la elección de los conceptos, así como las relaciones entre éstos y su significación en términos de poder (Van Dijk, 2011:17). De ahí que mediante el uso del ACD se trate de analizar cuidadosamente las diferentes estructuras del discurso, desde su temática hasta sus niveles descriptivos, significados e implicaciones de los conceptos, observando así su relación con un contexto ideológico de partida y el alcance social de su reproducción. En este marco, el discurso democrático en Marruecos debe entenderse no sólo como un discurso sobre la democracia, sino, más allá de su temática inmediata, como un discurso que dialoga con la historia, con la cultura y con la sociedad para expresar puntos de vista y aportar fundamentos teóricos y conceptuales susceptibles de solucionar los problemas de diferente signo a los que se enfrenta la sociedad marroquí 0 , al menos, contribuir a plantear alternativas intelectuales útiles en ese sentido. A partir de ahí, la democracia puede ser concepto generador de discurso y/o concepto de significación, dependiendo del marco ideológico de poder (arriba-abajo o abajo-arriba) que condiciona el discurso. La casuística diversa de las contribuciones de este monográfico permite, por tanto, aproximarse a diferentes ejemplos en los que esta relación resulta evidente.

Como afirma 'A. Gallāb, el pensamiento, como parte de la cultura, es necesariamente político y, por ende, el discurso intelectual en el contexto marroquí contemporáneo, también lo es (Gallāb, 1999:65) pues, en última instancia, reflexionar sobre la identidad, la cultura, la modernidad, la sociedad o el propio pensamiento es hacerlo sobre la democracia.

La vinculación, por tanto, entre la historia de la democratización en Marruecos, sus rupturas, y discontinuidades, y el discurso democrático de los pensadores marroquíes, conforma una valiosa narrativa que cuenta, en el sentido activo mencionado antes por Genette (Genette, 1983:15) de diferentes maneras posibles la democracia en Marruecos y en el resto del mundo árabe. Esta narrativa formal o "modal" (Genette, 1983:12) puede ser claramente observada a lo largo de los últimos veinte años, si bien sus raíces se encuentran mucho más atrás, en un largo periodo que ha venido configurando las propias tendencias y transformaciones del pensamiento político en Marruecos, así como influyendo progresivamente, mediante un esfuerzo de adaptación y divulgación de los pensadores marroquíes más influyentes a través de sus textos, en la cada vez mayor conciencia democrática de la sociedad marroquí que, en última instancia, habría llegado a formar parte de su propia cultura ${ }^{5}$.

La historia como fundamento y proyección del discurso postcolonial en Marruecos: de la alternancia (1997) al empoderamiento de las protestas ciudadanas (2011-2017)

\footnotetext{
${ }^{5}$ En el sentido en el que Edward Said asume la fenomenología de la cultura desde el texto. A. A. Hussein afirma que "la vida cultural humana, a fin de cuentas, es la mente haciendo actos significativos en circunstancias socio-históricas concretas" (Hussein, 2002: 98).
} 
La contextualización histórica de la democratización en Marruecos como fenómeno social, en primer término, y político, en segundo lugar, facilita la comprensión del discurso democrático, dado que es dicho discurso, fundamentado a partir de y proyectado hacia los acontecimientos históricos el que ha dotado a la democratización de un aparato teórico endógeno y autoconsciente. El proceso político, como tal, tiene en el discurso democrático una evidente referencia en cuanto a la propia conceptuación del mismo como proceso histórico. Al mismo tiempo, la influencia social del discurso democrático propone a la sociedad marroquí que demanda cambios económicos, sociales y políticos un marco teórico de referencia que fundamenta, a su vez, la acción social y política transformadora. El discurso, por tanto, se enmarca en la historia y se proyecta a la sociedad, que, a su vez, ejerce un papel histórico. Los pensadores árabes, en general, y marroquíes, en particular, como miembros de sociedades en cambio, tratan de analizar las características de dichos cambios para extraer elementos con los que conformar estructuras e ideas que contribuyan al progreso y al cambio. En el ciclo dialéctico de la idea y la acción, en el que puede cuestionarse, junto a A. Ayalon, si las ideas cambian la realidad o bien es la realidad la que transforma las ideas, es necesario recordar que el lenguaje, expresado en el texto y en el discurso que construye la narrativa, es el único medio de "captar" tanto la idea como la realidad en un contexto determinado (Ayalon, 1987: vii), pues al cambiar la historia, necesariamente el lenguaje la acompaña. Por tanto, en todo caso el lenguaje y el discurso tienen un sentido social y, como tal, ideológico ${ }^{6}$ (Van Dijk, 2011: 16-17).

En este sentido social puede afirmarse, siguiendo a Hanssen con cierta prudencia, que el pensamiento árabe ha puesto muchas trabas al autoritarismo en diferentes contextos (Hanssen, 2018), pues ha sido capaz de imaginar posibilidades y crear conceptos nuevos para dotar a las sociedades árabes de un discurso transformador de cambio social y democracia que, paulatinamente, ha pasado a formar parte del movimiento social en diferentes niveles. El pensamiento marroquí contemporáneo es diverso en su sistematización de la realidad social y política de Marruecos, así como dinámico en su comprensión de los fenómenos socio-históricos, y el papel del intelectual árabe no deja de ser ambivalente $y$, en ocasiones, controvertido. La historia, en este sentido, reclama ser protagonista en todos los casos, pues es la que da sentido a la conceptuación en el discurso. Sin embargo, si aplicamos una perspectiva post-orientalista y post-colonial, percibimos que la historia intelectual marroquí continúa teniendo un inequívoco carácter lineal, en consonancia con una historiografía eurocéntrica y sincrónica plenamente asimilada, así como una filiación estructuralista. Ambos elementos, linealidad histórica y estructuralismo, son entendidos por parte de los pensadores marroquíes como paradigmas de la modernidad intelectual y en ningún caso como elementos neocoloniales. Lejos de percibirse como "orientales subalternos", los pensadores marroquíes desarrollan un esfuerzo singular en la búsqueda de dos elementos relacionados: la modernidad (al-ḥadāta) y la identidad (al-huwiyya), tanto en el plano cultural, como en el político, que permita superar el estricto marco epistemológico. Así, la historia del Marruecos contemporáneo justifica esta doble adscripción lineal y estructuralista como un movimiento intelectual que no es esencialmente auto-percibido

\footnotetext{
${ }^{6}$ Fred Halliday, en su clásico estudio sobre las relaciones entre ideología y poder del estado en Oriente Medio, utiliza el concepto "ideología" con el sentido de "sets of beliefs concerning social and political issues, which are both explanatory and normative, that is, which purport to explain why the world is as it is, how it came to be so, and what the goals of political action should be" (Halliday y Alavi, 1988:5). En el mismo sentido Nikki R. Keddie afirma que en el ámbito intelectual árabe contemporáneo la ideología se compone del elemento "otro" y del elemento "clase". En función del contexto histórico-político, estos elementos se combinan de diferente manera, acomodando conceptos heteróclitos según las situaciones y las necesidades (Keddie, 1988:13-14).
} 
como subalterno, sino que de manera más amplia difumina los contornos de la periferia subalterna a través del estrecho contacto histórico, intelectual y sentimental con el centro colonial en un movimiento de ida y vuelta, desde el estructuralismo al post-estructuralismo, del Magreb a Francia y de ahí al Magreb nuevamente (Ahluwalia, 2010). Como objetivo último de la modernidad intelectual, en sentido político, la democracia se establece como el concepto fundamental de análisis. Así, la democratización sería un paso lógico en la proyección de dicha modernidad, lo cual tiene un claro reflejo en el discurso intelectual del pensamiento marroquí contemporáneo.

La condición post-colonial, por tanto, es asumida en el pensamiento marroquí contemporáneo como una condición histórica, pero, contrariamente a la identificación establecida por $\mathrm{H}$. Dabashi entre post-colonialismo, post-ideología y post-orientalismo (Dabashi, 2009), que implica el fin de la colonialidad como condición de la producción del conocimiento, el pensamiento marroquí experimenta el post-colonialismo en términos históricos y conceptuales de ida y vuelta y nunca en términos post-ideológicos. Como pensamiento, el magrebí tiende sin duda a la universalidad, pero la preeminencia de determinados conceptos en su discurso se debe a la necesidad de posicionamiento ideológico en un contexto determinado por la urgencia social y política. Es innegable, por tanto, la dificultad de desarrollar un ámbito post-ideológico para asentar la teoría post-orientalista en un contexto marcado por la ausencia de la definición de la identidad cultural oriental como intelectualmente válida. El pensamiento marroquí, en esencia, no participa de una reivindicación de lo oriental, pues tampoco asume plenamente la condición post-colonial en ese sentido.

Dicho esto, la categoría de subalternidad está presente como tal en el ámbito epistemológico y más ampliamente cultural en Marruecos, si bien de forma implícita en algunos casos. Las ideologías post-coloniales en el ámbito magrebí se han configurado como un proyecto pragmático que responde dialécticamente al proyecto desarrollado por el colonialismo, por lo que, fundamentalmente, son coloniales en su disposición y en su estructura conceptual en el discurso. Desde este parámetro, el proceso histórico y discontinuo de democratización en Marruecos ${ }^{7}$ tendría un punto de inflexión en el controvertido y estratégico gobierno de la llamada "alternancia" formado por 'Abd al-Raḥmān Yūsufí tras las elecciones legislativas de 1997 (Benmessaoud Tredano, 2000; Parejo Fernández, 2010), por el que por primera vez se formaba "un Gobierno de coalición dirigido por uno de los líderes históricos de los partidos de oposición, el socialista A. Yusufi. Este Gobierno contaba con el apoyo de una heterogénea mayoría parlamentaria formada por siete partidos políticos cuyas señas de identidad deben buscarse más en las trayectorias y relaciones históricas de sus líderes con el régimen alauí, que en sus contenidos ideológicos y programáticos" (Desrues y Moyano, 2000: 265). El proceso vivido por la sociedad marroquí desde dicha "alternancia" hasta el estallido de las protestas del 20 de febrero de 2011 (atendiendo al progresivo protagonismo de la sociedad civil) (Pérez Beltrán, 2006; Sater, 2007) podría ser entendido desde una lectura dabashiana como un proceso histórico que constataría de manera progresiva la conciencia de subalternidad y la puesta en marcha determinados mecanismos para la subversión de la misma. Para Dabashi dicho proceso tendría un

\footnotetext{
7 En relación con la continuidad histórica de los hechos políticos “democratizadores" en Marruecos entre 1999-2011, Mohammed Darif aporta una cronología contextualizada de la "transición a la democracia" que relaciona, por una parte, con un conflicto de legitimidades y, por otra, con los procesos de reforma política, descentralización y reforma constitucional (Darif, 2014: 105-124).
} 
carácter post-ideológico en cuanto plantea la posibilidad de una nueva modernidad post-colonial y de la superación de las narrativas eurocéntricas. A pesar de que es evidente una lectura subversiva de la subalternidad en este proceso, los pensadores marroquíes, sin embargo, no identifican dicho proceso como post-ideológico, pues a pesar de la condición de colonialidad, identifican la ideología con una necesidad del pensamiento marroquí y árabe que implica la voluntad y la acción. La clave de la superación de la subalternidad, para ellos, está en la autoconciencia ideológica (alwa'î I-dātî) que es ontológica y es política, y no en la superación de las ideologías (Dabashi, 2009:126). En esta misma línea cabe señalar que el marco histórico inmediato de los autores se sitúa en el contexto de la democratización señalado, si bien como pensamiento tendente a la universalidad y a la arabidad, la narrativa intelectual marroquí también está compuesta de contradiscursos cuyo eje primario es el colonialismo, desde el análisis del proceso histórico colonial hasta la globalización, pues la contestación a estos procesos supone la construcción de una narrativa democrática que completa la historia y significa plenamente el discurso. Con respecto a la democracia, la dialéctica ideológica que construye las narrativas alternativas juega en ambos sentidos, de manera proactiva y de manera reactiva. El resultado, por tanto, es una narrativa democrática que, siendo muy anterior en términos cronológicos a las revueltas árabes de 2011, ha ido construyéndose como un espacio de libertad, como "islas de democracia" (Parejo, 2005:77), con elementos diversos y dinámicos, influyendo progresivamente en el tejido social y en la ampliación de espacios intelectuales, sociales y políticos de libertad ${ }^{8}$.

\section{Las narrativas alternativas: modernidad y democracia en el discurso del pensamiento marroquí contemporáneo}

A partir de aquí, puede plantearse un análisis crítico del discurso democrático que, teniendo en cuenta los elementos conceptuales/léxicos como eje fundamental, profundice en la concepción ideológica de los acontecimientos históricos en el periodo mencionado, teniendo en cuenta la relación dialéctica entre idea y realidad, es decir, entre discurso e historia. Para ello se han seleccionado convenientemente las obras de tres autores destacados del Marruecos contemporáneo cuyas narrativas constituyen auténticas alternativas. Los tres autores seleccionados en este trabajo, a saber, Kamāl 'Abd al-Lațîf, Ṭāhā 'Abd al-Raḥmān y Muḥammad 'Ābid al-Ŷābrī, comparten varias características en común. Entre ellas, la decidida intención de actuar en la sociedad árabe y marroquí a través de sus obras. Es decir, la ideología en ellos se relaciona con los valores democráticos y, por tanto, con la necesidad de la acción y el cambio social. En los tres pensadores se condensa la altura y la vitalidad de la cultura marroquí; los tres utilizan el árabe como lengua del pensamiento y la cultura y por ello su influencia ha trascendido al ámbito internacional, pues sus obras son publicadas, conocidas y ampliamente difundidas en todo el mundo árabe. Los tres autores, comprometidos por tanto con los valores democráticos y la cultura árabe, proponen una misma búsqueda de la modernidad árabe y marroquí, modernidad que, también como narrativa, se construye en relación con la antropología (identidad, cultura) y la política (democracia, sociedad civil, derechos humanos).

Como elementos de diversidad, por otra parte, pueden citarse su pertenencia a generaciones diferentes, especialmente evidente en los casos de Kamāl 'Abd al-Lațîf, el más joven de los tres, y

\footnotetext{
${ }^{8}$ El sociólogo y pensador egipcio al-Sayyid Yasīn (1933-2017) abordaba ya a finales de los años noventa la relación entre renovación intelectual y progreso político como uno de los grandes temas de desarrollo del mundo árabe "futuro" en relación con el contexto de la globalización y la problemática de la auto-objetivación (Yasīn, 1998: 43-47).
} 
Muḥammad 'Ābid al-Ŷābrī (1935-2010). Como se verá, su discurso democrático difiere en el elemento conceptual que canaliza su narrativa alternativa: en el caso de Kamāl 'Abd al-Lațif, el concepto central de su discurso es la modernidad política; en el caso de Ṭāhā 'Abd al-Raḥmān, este concepto será el de modernidad ética; y en el caso, finalmente, de Muhammad 'Ābid al-Ŷābrī, será el de democracia social. Cada uno de estos conceptos dará lugar a un discurso ideológico sobre la democracia que construirá tres narrativas correspondientes, siempre entendidas en su sentido dialéctico y práctico: una narrativa política, una narrativa ética y una narrativa social. Estas narrativas debe ser entendidas en relación con el papel tradicionalmente comprometido $y$ controvertido del intelectual en Marruecos y el mundo árabe, y contextualizadas en la relación que vincula el discurso intelectual, siguiendo a A. Belqazīz, con el conocimiento (al-ma'arifa), la sociedad (al-muŷtama') y la autoridad (al-sulța) (Belqazīz, 1999: 9). Como transmisor de conocimiento, el discurso intelectual es el fundamento de las ideas que se generan y transmiten al ámbito social, donde se convierten en ideas transformadoras que llegan a lo político y a lo jurídico como referencia de determinadas aspiraciones o derechos, sobre los que la autoridad política puede tomar una postura favorable o contraria. En esta relación puede subvertirse el principio de autoridad, de ahí la importancia del intelectual en los países árabes y su papel en muchos casos ambivalente, como destaca E.S. Kassab en su análisis del intelectual árabe y su relación con el surgimiento de las revueltas de 2011 (Kassab, 2013). Las narrativas política, ética y social representadas por estos autores son por tanto la plasmación concreta de esta relación en un contexto determinado como el marroquí a lo largo de los últimos veinte años.

\section{Kamāl ‘Abd al-Lațîf y la narrativa política}

Kamāl 'Abd al-Lațîf, profesor de filosofía política y pensamiento árabe contemporáneo en la Universidad Muhammad $V$ de Rabat, es uno de los pensadores marroquíes más destacados de las últimas décadas y sin duda uno de los más influyentes en el exterior, como puede comprobarse en la abundancia de sus publicaciones en medios árabes internacionales y en las numerosas ediciones de sus obras en prestigiosas editoriales árabes fuera de Marruecos. 'Abd al-Lațîf es quizás el último representante, por el momento, de la conocida como "escuela filosófica de Rabat" (Macías Amoretti, 2009:186) que en el Departamento de Filosofía de la Universidad Muhammad V se inició en torno a la figura de Muḥammad 'Azīz Laḥbābī (1922-1993) a finales de los años 60. En una línea de continuidad metodológica de pensamiento crítico, 'Abd al-Lațîf estaría vinculado a la misma a través de su maestro y mentor Muḥammad 'Ābid al-Ŷābrī, que sería después de Laḥbābī la gran figura de referencia de dicha escuela.

La obra de Kamāl 'Abd al-Lațîf se ha centrado desde los años 90 en la revalorización del campo intelectual y filosófico marroquí, dedicando algunas de sus obras más importantes a analizar los trabajos de pensadores como el propio al-Ŷābrī, Ṭaha 'Abd al-Raḥmān o 'Abd Allāh Laroui, entre otros'. A partir de estas obras, Kamāl 'Abd al-Lațîf ha tratado de hacer frente a los cuestionamientos y necesidades más urgentes de la sociedad marroquí y de las sociedades árabes en general, tratando de potenciar el elemento racional y reforzar la base epistemológica del pensamiento árabe y magrebí contemporáneo. Estas obras se han complementado con aquellas

\footnotetext{
${ }^{9}$ Entre ellas, cabe destacar Dars al-'Arwī fĩ l-difā' 'an al-fikr al-tārījī (Lección de Laroui sobre el pensamiento histórico, 2000), al-Turāt wa-I-nahḍa: qira'āt fí a'māl Muhammad 'Ābid al-Ŷābrī (El turāt y la nahḍa: lecturas de las obras de Muḥammad 'Ābid al-Ŷābrī, 2004) o al-Fikr al-falsafí fĩ l-Magrib al-'Arabī: qirā'āt fĩ a'māl al-'Arwī wa-l-Ŷābrī (El pensamiento filosófico en el Magreb: lecturas de las obras de Laroui y al-Ŷābrī, 2008).
}

REIM No 25 (diciembre 2018) ISSN: 1887-4460 
destinadas a la reflexión sobre la conciencia del ser intelectual árabe en el marco histórico y cultural concreto. Para 'Abd al-Lațif, la lectura histórica entronca con la colonialidad y la postcolonialidad, en el sentido en el que era entendida por el pensador argelino Mālik Bennabī (Macías Amoretti, 2012). Para 'Abd al-Lațîf, el contexto de la democratización, en sentido ideológico, está necesariamente vinculado al post-colonialismo. La necesidad de liberación del ser árabe y marroquí como sujeto colonial es, en primer término, intelectual. De ahí su intento constante de atender a la riqueza del propio pensamiento marroquí para, en este contexto, dirigirse a los marroquíes y a los árabes como sujetos históricos conscientes. En su obra Iškāliyyāt al-jițāb al'arabī l-mu'āșir (Problemáticas del discurso árabe contemporáneo), de 2001, trataba, junto al politólogo iraquí Nașr Muḥammad 'Ārif, de dar una respuesta a la permanencia ideológica del pensamiento árabe contemporáneo. Dicha respuesta tenía necesariamente que pasar por la comprensión histórica de las ideologías y, por tanto, por la autoconciencia histórica del propio discurso árabe como discurso ideológico, elemento constantemente problematizado en el pensamiento árabe contemporáneo, pero aún irresuelto. Por tanto, esta es una de las claves esenciales del edificio discursivo de 'Abd al-Lațîf: "El auge del imperialismo occidental en el siglo XIX incidió en la construcción de las referencias del discurso emergente y contribuyó a la reconstrucción de las formaciones sociales e históricas que acompañaron el desarrollo y la cristalización de este discurso" ('Abd al-Lațîf y 'Ārif 2001: 128-129).

Es evidente que para 'Abd al-Lațîf, el discurso "cristaliza" (tabalwur) la relación entre la historia y pensamiento y, por tanto, no puede ser ajeno a sus condicionantes ideológicos. En este sentido, el discurso asume la complejidad histórica como una característica asumible y no necesariamente negativa, sino puramente descriptiva, cuyo objetivo ideológico para 'Abd al-Lațîf es la constatación del hecho histórico y su influencia definitiva en el pensamiento árabe. El elemento, por tanto, generador del discurso en 'Abd al-Lațîf es la historia. Desde el punto de vista ideológico, el concepto generador de significado es la autoconciencia del ser colonial, también en el pensamiento. Es desde esta autoconciencia colonial del pensamiento árabe desde la que puede construirse un discurso crítico alternativo y plenamente post-colonial. Con respecto a la colonialidad y a la posibilidad de subvertirla como condición, 'Abd al-Lațíf asume como elemento histórico en el momento contemporáneo el proceso post-colonial leído como un fenómeno moderno y, por tanto, relacionado directamente con la propia historia del pensamiento árabe contemporáneo. La historia colonial se presenta para 'Abd al-Lațif como un hecho característico que conforma el "yo" árabe, tanto en el discurso como en lo que él denomina la "realidad" (al$\left.w \bar{a} q i^{\prime}\right)$.

Desde un postulado claramente estructuralista, esta relación es necesariamente ideológica, en tanto persiste como problemática fundamental del pensamiento árabe contemporáneo la negación de la conciencia colonial. Es decir, 'Abd al-Lațîf asume la relación entre el "yo" árabe y marroquí y el "otro" imperialista (y neocolonialista), no en términos de exclusión o de negación, como de hecho ha sido habitual en determinadas ideologías políticas árabes como el nacionalismo o el islam político, sino en términos dialécticos. La definición del "yo" en el discurso árabe no puede ser exclusivamente la negación excluyente del "otro" en términos de "polarización" o de "categorización Nosotros-ellos" (Van Dijk, 2011:122), sino que debe construirse desde la autoconciencia de la "otredad" presente en el discurso intelectual y en la práctica social y política. Esto es el núcleo mismo de su narrativa política entendida como post-colonial, pues es la postcolonialidad la que da sentido a su discurso ('Abd al-Lațîf y ‘Ārif 2001:130).

Este argumento se relaciona en 'Abd al-Lațîf con el comienzo de la crítica al proceso de modernidad post-colonial desde finales de los años noventa. Desde entonces, el pensador 
marroquí se plantea esta relación ideológica en términos muy concretos. Su objetivo es diagnosticar las dificultades ideológicas del discurso político en el mundo árabe y, a partir de ahí, elaborar un pensamiento autoconsciente de su diversidad y de sus complejidades, más allá de la elaboración de un simple discurso político de opuestos. Entre estas dificultades destaca el peso de la colonización intelectual a través del sistema estructuralista como centro de un discurso y un proyecto de acción que supone la necesaria oposición a otro. La identidad colectiva es un elemento fundamental en este sistema, generándose asimismo en términos de negación, especialmente al extrapolarla al campo de las ideologías e identidades políticas que se suceden en Marruecos desde los años noventa. Consciente de las transformaciones culturales, sociales, económicas y políticas y de las dificultades del contexto colonial y neocolonial, 'Abd al-Lațîf plantea la necesidad de revisar de manera amplia y honesta la relación del discurso con la historia en términos ideológicos:

"La Segunda Guerra del Golfo dio una nueva imagen a la problemática de los árabes y Occidente (...), transformando cualitativamente la naturaleza de las relaciones entre Occidente y nosotros. Nuestro conflicto moderno con Occidente comenzó hace aproximadamente dos siglos. En ese contexto, el imperialismo llevó al capitalismo europeo a alcanzar una fase de rapiña exterior hacia nuevos mercados y materias primas, tomando luego nuevas formas según sus intereses. Entonces, los movimientos nacionales árabes lo desafiaron con sus aspiraciones de liberación" ('Abd al-Lațîf 1997:10)

La base histórica es necesaria, por tanto, para la autoconciencia política. Tras la exposición de los orígenes estructurales de la relación ideológica como elemento fundamental, 'Abd al-Lațîf continúa analizando esta relación a lo largo de la historia, llegando desde el colonialismo hasta las revueltas árabes. Existe, por tanto, una clara concepción de la linealidad histórica. Sin embargo, esta linealidad está marcada por continuidades y rupturas que conforman, en todo caso, elementos narrativos en los términos señalados. Así, desde la colonización hasta las revoluciones árabes, según 'Abd al-Lațîf, existe una continuidad histórica de la democracia en el discurso, si bien las rupturas políticas (colonialismo, independencia, crisis del estado, etc.) han impedido en determinados momentos históricos que dicho discurso fraguara en una concepción social del cambio capaz de transformar la realidad. A pesar de ello, la contextualización histórica de los acontecimientos es situada caso en el centro del discurso, dado que, como se ha visto, existe una dialéctica fundamental entre concepto e historia que está constantemente presente en la narrativa democrática desarrollada por 'Abd al-Lațîf.

El punto de inflexión histórico, por una parte, lo encuentra 'Abd al-Lațîf en el estallido de las revoluciones en 2011 como continuación de las aspiraciones democráticas y encuentro de discurso intelectual y práctica social. No obstante, si bien es indudable la centralidad del contexto revolucionario, para Kamāl 'Abd al-Lațîf los procesos de democratización tienen un alcance ideológico y discursivo muy anterior, pues están fundamentados, en el discurso y en la práctica, en las transformaciones sociales y las demandas económicas y sociales de las últimas décadas. De ahí que surja la necesidad de reflexionar y revisar algunos de los postulados intelectuales que habían ido construyendo el relato narrativo de la democracia en el mundo árabe:

“El año 2011 supone un punto de inflexión histórico y cualitativo en las transformaciones vividas por la sociedad árabe a principios de la segunda década del 
tercer milenio, pues pocos países fueron reticentes a cambiar de dirección hacia un proyecto democrático para sus regímenes políticos. Ciertamente, la mayoría de estas sociedades ya había conocido en su historia reciente determinadas iniciativas y dinámicas dirigidas a derrocar a los regímenes en el poder; sin embargo, lo conseguido en 2011 gracias a la persistencia y a la enorme audacia de la mayoría de las plazas y ciudades árabes, puede considerarse la culminación de largas décadas de protestas, especialmente intensificadas en las dos últimas décadas en Egipto, Túnez y Marruecos, al mismo tiempo que se intensificaba la respuesta violenta de los regímenes en la mayoría de países árabes" ('Abd al-Lațîf, 2016:27)

Es evidente que en el análisis de este fragmento puede encontrarse la identificación de la linealidad histórica en el discurso de "Abd al-Lațîf cuando menciona la "culminación" (tatwîy) del proceso histórico de democratización lo que, en cierta medida, coincide con la "culminación" de su narrativa democrática, defendida desde los orígenes de su discurso como una necesaria toma de conciencia democrática del ser post-colonial. Es decir, se sitúa intelectualmente en la postcolonialidad histórica como forma de afrontar de manera integral la identidad post-colonial desde la conciencia histórica de la colonialidad, lo que supone para 'Abd al-Lațîf el núcleo de un auténtico y profundo cambio cultural que debe producirse en el mundo árabe. Dicho cambio cultural se relaciona con la asunción de la identidad post-colonial que, para él, implica la auténtica asunción de la modernidad plena y compartida como resultado de la crítica histórica y cultural ('Abd al-Lațîf, 1997:20). La tesis claramente defendida por el autor sustenta la idea de la persistencia (resiliencia) histórica de las aspiraciones democráticas de las sociedades árabes a lo largo de las últimas décadas, al tiempo que justifica la existencia del discurso democrático y su identificación con dichas aspiraciones. Su crítica implícita aquí al "fin de la Historia" propugnado por F. Fukuyama confirma lo que había sido una crítica explícita veinte años antes ('Abd al-Lațîf, 1997: 39), dando por tanto un sentido completo a su narrativa. Es interesante, en este sentido, el hecho de que en esta obra editada en Beirut y distribuida para todo el mundo árabe, el autor haga mención de las dos últimas décadas (1997-2016) como especialmente significativas para la consecución de los espacios democráticos, al mismo tiempo que, entre los escenarios marcadamente revolucionarios que cita, evidente en los casos de Túnez y Egipto, sume también el caso de Marruecos. Es decir, la narrativa democrática de 'Abd al-Lațîf sitúa Marruecos como un escenario privilegiado de democratización, tanto por su posición intelectual como por la acción política democratizadora de su sociedad.

\section{2. Ṭāhā ‘Abd al-Raḥmān y la narrativa ética}

Ṭāhā 'Abd al-Raḥmān (n. 1944) ha dedicado su labor filosófica a dos ámbitos fundamentales: por una parte, a la filosofía del lenguaje en sentido amplio, incluyendo la filosofía de la traducción; por otra parte, a la ética como fundamento principal de la filosofía práctica. Ambos campos son, en su estructura filosófica, ciertamente complementarios, pues permiten abordar la dimensión social del pensamiento en dos componentes relacionales fundamentales: la lengua como sistematización y expresión de ideas y sistema de comunicación en el ámbito social, y la ética como moral social. Su narrativa, por tanto, parte de la crisis de la escritura filosófica en el ámbito social, para poder analizar y contextualizar los conceptos del pensamiento, poniendo fin a dicha crisis. Su idea de modernidad entronca con el cuidado en la elección de los conceptos, el lenguaje y la escritura filosófica. A partir de ahí, su foco se centra en la ética como base de la modernidad y del cambio cultural árabe e islámico en un esfuerzo de reconstrucción social e histórico que parte de la consideración de la moral como fundamento de una sociedad moderna y avanzada. La originalidad 
de 'Abd al-Raḥmān estriba precisamente en dedicar a la ética el esfuerzo crítico, hermenéutico y práctico que otros pensadores han dedicado a la política (Macías Amoretti, 2009:195). Para él, la modernidad no puede estar circunscrita a las identidades líquidas o a la cultura materialista, sino que debe estar sustentada en un sistema de valores firme que, en la propuesta de 'Abd alRaḥmān, se asientan en los valores del islam. Aunque ligada a los valores del islam, la ética es preconizada por 'Abd al-Raḥmān como uno de los fundamentos de la humanidad, de lo que, en palabras de “Abd al-Lațîf, "humaniza al ser humano" ('Abd al-Lațîf, 2003:140) más allá de su inmediata adscripción cultural, y le hace entrar en la historia. Por tanto, en esta narrativa ética, el ser árabe, como ser social, es concebido como un ser moral, racional e histórico, que fundamenta su existencia en estos ámbitos a partir de un conjunto de valores espirituales y racionales que, en tanto tales, son universales. No obstante, 'Abd al-Raḥmān ejerce una crítica frente a la imposición de valores culturales dominantes, léase exógenos, pues considera que el sistema de valores no puede ser impuesto porque deja de ser racional. Los valores que sustentan, o deben hacerlo, la modernidad islámica, árabe y marroquí, son valores universales en tanto islámicos.

Desde finales de los años noventa del siglo XX, 'Abd al-Raḥmān efectúa una fuerte crítica de la globalización neoliberal (al-'awlama), en la que se sitúa su discurso intelectual. Dicha crítica se fundamenta en dos elementos fundamentales: el cultural-identitario y el axiológico. Por una parte, la globalización fuerza a la uniformidad cultural impuesta por un espíritu materialista vinculado con el colonialismo y el neoliberalismo. Las identidades no hegemónicas en este marco histórico tienden a diluirse y a desaparecer en favor de una hegemonía uniforme. Por otra parte, el reflejo de esta licuefacción identitaria en el ámbito axiológico es la crisis de valores éticos y morales, superados por la lógica acumulativa y deshumanizadora que acompaña al proceso de la globalización. La respuesta que Ṭāhā 'Abd al-Raḥmān propone es, por tanto, una respuesta de urgencia, defensiva en todo caso, proponiendo una nada fácil salida a esta doble licuefacción de identidad y valores a través de un nuevo enfoque de la modernidad endógena. A pesar de ser endógena en el sentido epistemológico, es decir, en la mirada introspectiva hacia la (re)construcción de la identidad colectiva, en lo metodológico 'Abd al-Raḥmān propone una apertura dialógica al "otro" que no parte del rechazo, sino del encuentro abierto y sin renuncia. Para él se trata de promover una nueva modernidad o, en su propia conceptuación, un nuevo "espíritu" (rūḥ) que funde una modernidad auténtica ('Abd al-Raḥmān, 2009). Dicho espíritu tiene tres fundamentos básicos, que son: integridad (rušd), crítica (naqd) e inclusión (šumūl). Así, considera que "el fundamento de la modernidad es la transición desde el estado de insuficiencia y limitación hasta el estado de integridad (rušd)" ('Abd al-Rāḥmān, 2009:25). Relacionado con el pensamiento kantiano y aristotélico, se trataría de alcanzar definitivamente una modernidad "en acto" que ya está presente "en potencia" en las sociedades árabes. Dicho de otro modo, la sociedad árabe ya es moderna, pero no ha alcanzado la modernidad. En el mismo sentido, otro fundamento de la modernidad para 'Abd al-Raḥmān es "el paso de un estado de (auto)convicción a un estado de crítica (intiqād)" ('Abd al-Raḥmān, 2009:26). El paso de lo limitado a lo integral pasa necesariamente por el paso de las certezas a los cuestionamientos que hacen de la crítica y la autocrítica, basada inquebrantablemente en la razón, el eje de la modernidad. Finalmente, el último "paso" a la modernidad lo constituye, como tercer fundamento, "salir del estado de particularidad (ḥāl al-jușūș) hacia el de inclusión” ('Abd al-Raḥmān, 2009: 28). En su propuesta, 'And al-Raḥmān concibe la modernidad como una transición que, en este sentido, permite abordar la globalidad desde una perspectiva nueva, no centrada en la limitación o la exclusión del "yo" o del "otro", sino en la apertura al otro desde la conciencia plena de sí, el autoconocimiento crítico y 
racional y, a partir de ahí, mediante el diálogo y el encuentro. En el contexto del cambio de siglo, la globalización es definida como "una forma de entender el mundo que pone en relación las sociedades y los individuos mediante tres modos de control: el control de la economía en el ámbito del desarrollo, el control técnico en el ámbito de la ciencia y el control de la red en el ámbito de la comunicación" ('Abd al-Raḥmān, 2009:78); en este contexto, el esfuerzo intelectual ya no consiste en ir de la tradición a la modernidad, según el concepto de "mutation culturelle" de Paul Khoury (Khoury, 2012:35), sino que se trata de una tarea mucho más compleja que se manifiesta en un discurso post-moderno, en el sentido estructural, que es consciente de sí mismo y crítico con el control que ejercen estas "modernidades" ideológicas e ideologizadas, asumidas o estigmatizadas, sobre las sociedades árabes y sus individuos.

En el discurso de 'Abd al-Raḥmān, esta transición entre modernidades se concreta en el paso de una modernidad falible, líquida o falsa (muqallad) hacia una modernidad original y creativa (mubdi'). Nuevamente, en el discurso aparece el concepto generador de significado "liberación", puesto que los condicionantes que dificultan la transición hacia la modernidad original, son las diversas tutelas (wișāya) y peajes que son impuestos a las sociedades árabes tanto en el exterior como dentro de las propias dinámicas sociales autóctonas. El elemento autocrítico, por tanto, es explícito en 'Abd al-Raḥmān, en consonancia con su propia teoría de la modernidad. Una de las liberaciones más importantes, en este sentido, es la liberación del Islam de la tutela de sus intérpretes tradicionales. El acceso a la modernidad pasa por superar este obstáculo y servirse del islam como fundamento conceptual, cultural y axiológico de una modernidad alternativa. Parecería que la "alternativa islámica" estaría construida a nivel histórico por las construcciones ideológicas que han vertebrado determinados movimientos políticos a lo largo del último siglo. Sin embargo, 'Abd al-Raḥmān encuentra en el islam una inspiración que va más allá de lo inmediato si se utiliza la razón como método fundamental de análisis.

Así, de acuerdo con la definición de globalización aportada, el islam es el único fundamento posible de liberación en los tres ámbitos de control señalados. Tanto en el ámbito económico, como en el técnico y en el de la comunicación, el islam aporta un recurso esencial que permite romper los mecanismos de control y liberar al individuo y, por ende, a sus sociedades de manera colectiva. Dicho recurso es la ética. El cambio de las relaciones de control entre individuos y sociedades por una nueva relación basada en la ética permite contemplar con una nueva luz los ámbitos de la economía, la tecnología y la comunicación. 'Abd al-Raḥmān no aboga por una revolución política, dado que contempla las estructuras de la modernidad globalizada como estables. Sin embargo, la propuesta de transformar las relaciones de poder y coerción por relaciones éticamente justas, tiene elementos revolucionarios que construyen sin duda una narrativa democrática basada en la justicia ('adl) como valor moral supremo.

Por tanto, su discurso se adentra en una metodología eminentemente filosófica para profundizar en las complejidades identitarias y culturales del ser marroquí, que, en relación con esta modernidad política, ética y cultural, atraviesa multitud de identidades que le son propias y no son excluyentes, como aparecen en otros discursos de la modernidad. Para 'Abd al-Raḥmān, la dicotomía entre dos antropologías culturales no es ontológica, pero resume la persistencia de identidades complejas, ahistóricas y constantemente reinventadas que tienen asimismo una vinculación directa con el campo político y con la concepción del cambio social. Es decir, tienen una lectura profundamente democrática. Țāhā 'Abd al-Raḥmān reafirma la importancia de entender la complejidad antropológica y política del ser magrebí como una diversidad positiva, propia y plenamente moderna en todos los sentidos ('Abd al-Raḥmān, 2006). 


\section{Muḥammad 'Ābid al-Ŷābrī y la narrativa social}

Desde el discurso antropológico al puramente político, el filósofo Muḥammad 'Ābid al-Ŷābrī, lejos de caer en la atracción del intelectual orientalizante, aporta una perspectiva liberadora desde el post-estructuralismo de raíz faucaultiana y la arqueología filosófica, siempre definiendo su metodología en relación con el contexto histórico y con los objetivos últimos de su reflexión. Para él, la democracia "política" tiene una connotación ciertamente liberadora en lo histórico (al-Ŷābrī, 1997), y es a partir de este concepto desde el que al-Ŷābrī pretende construir, en positivo, un auténtico proyecto de resurgimiento, que es a la vez intelectual y reformista en lo social. El proyecto nahd̦awi árabe que define y defiende a lo largo de toda su producción en el contexto histórico de la alternancia y la democratización en Marruecos y la mundialización, es un proceso intelectual de búsqueda y encuentro que abarca toda su obra, y que la hace, en buena medida, concreta y cercana a la sociedad a la que pertenece (al-Ŷābrī, 2000). No es casual que en este proceso histórico, el discurso de al-Ŷābrī se encuentre entre las principales referencias intelectuales de un sector de la izquierda marroquí, así como de una parte del liderazgo de las protestas sociales de $2011^{10}$. En cierta medida, la propia popularidad del discurso democrático de al-Ŷābrī da cuenta de su declarada vocación de conformar un fundamento teórico para la sociedad civil marroquí, a lo que dedicó parte de sus últimas publicaciones en su última década de vida ${ }^{11}$.

El discurso de al-Ŷābrī, por tanto, tiene una clara incidencia social, construyendo una narrativa que se nutre de una conceptualización fuertemente vinculada a la idea de modernidad y progreso social y político. En todo momento, el desarrollo teórico e ideológico de al-Ŷābrī se centra en la sociedad como sujeto de acción colectivo y como objeto del proyecto de cambio. Según él mismo afirma, la sociedad árabe debe ser el objeto del análisis teórico, dado que si se obvia la realidad social, cualquier proyecto ideológico está abocado al fracaso (al-Ŷābrī, 2005). No cabe duda de que este planteamiento puede situarse en la línea del pensamiento subalterno, en cuanto la sociedad árabe es considerada actor de desarrollo y es vinculada a la necesidad de transformar el conocimiento en acción. Subvertir la autoridad en él ámbito intelectual, en este sentido, significó para al-Ŷābrī deconstruir el turāt en búsqueda de los elementos originales de una estructura de conocimiento árabe válida como fundamento de una modernidad árabe plena, racional y consciente. No exenta de polémica ${ }^{12}$, su propuesta contenida en los cuatro volúmenes de su obra fundamental Naqd al-'aql al-'arabī (al-Ŷābrī, 1984-2001) sigue constituyendo una de las obras cumbre del pensamiento árabe contemporáneo.

\footnotetext{
${ }^{10}$ Entrevista con líder juvenil del Movimiento 20-F, Rabat (05/04/2011). Al-Ŷābrī fue uno de los pocos referentes intelectuales árabes y marroquíes citados por el entrevistado, si bien con cierto escepticismo, junto a otros provenientes de tradiciones intelectuales ligadas a la izquierda y a los movimientos sociales como Antonio Gramsci y Gene Sharp.

${ }^{11}$ Cf. Especialmente la colección Mawāqif, iḍā'āt wa-šahādāt publicada en Casablanca por Dār al-našr al-magribiyya entre 2002 y 2007, en la que pueden encontrarse pequeños ensayos dedicados a temas de importancia social, tales como la democracia, la sociedad civil, los derechos humanos, el papel de la monarquía, el hiŷāb, la política exterior norteamericana, etc. Todo ello en un formato y con un precio y distribución accesibles para buena parte de la población.

${ }^{12}$ Puede citarse en este sentido la agria polémica que mantuvieron al-Ŷābrī y el pensador libanés George Ṭarābišī (1939-2016), quien dedicó una obra a criticar extensamente la propuesta de al-Ŷābrī. Cf. Ŷūrŷ Tarābišī (1998): Iškālīyāt al-'aql al-'arabī: naqd Naqd al-'aql al-'arabī. London: Dār al-Sāqī.
} 
Para al-Ŷābrī es necesario plantear el análisis social desde el contexto marroquí y árabe, evitando otras referencias exógenas que no comparten las características culturales e históricas que, necesariamente, condicionan la realidad propia del pensamiento político árabe (Gallāb, 1993: 121). Entre ellas, al-Ŷābrī cita la importancia del elemento tribal (al-qabīla) que ha configurado ciertamente las relaciones sociales entre individuos y colectividades en el mundo árabe a lo largo de la historia. A pesar de ello, la individualidad en al-Ŷābrī tiene un papel destacado, pues son finalmente las libertades individuales las que pueden generar un proceso de reforma social que las garantice definitivamente, haciendo al individuo protagonista del desarrollo político mediante la conciencia, la ideología y la acción. Al igual que 'Abd al-Raḥmān, existe un fuerte componente ético en este discurso, si bien la moral deja paso a una fuerte ética social. Al-Ŷābrī se muestra especialmente preocupado por adecuar el análisis social a la realidad histórica, pues de otra manera no pueden darse las condiciones para la puesta en práctica del proyecto de cambio ético, social y político que engloba la democracia como "tarea histórica". Junto a la tribu, otros elementos que al-Ŷābrī considera necesario tener en cuenta en este sentido son la ausencia de una clase burguesa como tal y de una clase trabajadora consciente, así como la carencia de procesos de industrialización. Sin tener todo ello en cuenta, como advertía también Kamāl 'Abd alLațîf, se corre el peligro de alejar el pensamiento árabe moderno (ḥadīt) de la realidad árabe actual (rāhin) (al-Ŷābrī, 2004:140).

Evidentemente, en la construcción narrativa de al-Ŷābrī, un concepto fundamental es el de "estado" (dawla). El estado tiene un papel como actor político fundamental en el contexto árabe y marroquí contemporáneo, y su relación con la sociedad es necesariamente dialéctica. Para al-Ŷābrī el estado es producto del acuerdo histórico nacionalista y del proceso anticolonial, por lo que tiene un papel histórico y debe analizarse su relación con la sociedad. Así, el estado es consecuencia del proceso político nacionalista y debe ser garante del progreso social, nunca un obstáculo a las libertades y a la democracia, sino todo lo contrario. De ahí que, como antiguo dirigente de la Unión Socialista de Fuerzas Populares (USFP), el contexto de la "alternancia" sea observado por al-Ŷābrī como un momento de oportunidad en el proceso de cambio social y político vivido por Marruecos desde los años sesenta, pues lo considera crucial en la posibilidad de una nueva forma de relación explícitamente democrática entre estado y sociedad:

“La llamada 'alternancia' en el Marruecos de hoy consiste no solamente en un cierto retorno a la forma de formar gobierno que recuerda a la de los años 1958-1960, sino que significa sobre todo el recurso a un procedimiento, tal vez lento pero inevitable, que debe conducir a una sustitución pacífica del espacio político tradicional por un espacio verdaderamente moderno, es decir, verdaderamente democrático. En otras palabras, la vocación del gobierno de alternancia del que el Sr. Yusufi es Primer Ministro consiste, en el ámbito político, en dotar a la monarquía marroquí de un contenido verdaderamente constitucional y democrático" (al-Ŷābrī, 1999:135-136)

Así, al-Ŷābrī pretende diagnosticar el estado de la cuestión de la relación entre estado y sociedad en el que la sociedad se configura como actor clave y la medida última de la democratización "desde abajo". Para ello, partiendo de una contextualización de la alternancia marroquí no exenta de un optimismo tal vez excesivo, analiza el contexto de esta relación en el mundo árabe, en un esfuerzo de interpretación (iŷtihād) del pensamiento social e histórico. Dicho contexto está marcado por la necesidad de entender en toda su complejidad los procesos sociales, que es lo mismo que hablar de procesos ideológicos, políticos y económicos, entre los que destacan los siguientes (al-Ŷābrī, 2004: 162): 
a) La diversidad de la realidad económica y social de los contextos árabes, que han variado tradicionalmente entre el capitalismo, el socialismo y las economías tradicionales; b) la diversidad de la realidad intelectual e ideológica árabe, especialmente de las tendencias nacionalistassocialistas e islamistas; c) la complejidad de la realidades nacionales como concepto político y social, que para al-Ŷābrī es una única unidad compuesta por diferentes elementos; d) la polaridad de la realidad internacional actual, en la que el mundo árabe forma parte del "Sur", por oposición al "Norte" económico, cultural y político dominado por Estados Unidos y Europa.

Estos elementos forman parte de un análisis que, en el marco de los estudios de la postcolonialidad expone una realidad social árabe compleja y particularmente diversa en lo ideológico y en lo político. Una vez identificados estos elementos de manera genérica, al-Ŷābrī aboga por situarlos como base de un análisis integral y conjunto del que puedan participar las diferentes tendencias ideológicas árabes, de una manera amplia. De esta manera, partir de un análisis social compartido supone aceptar un mismo contexto, partir de una misma historia, abriendo la posibilidad a construir discursos diferentes. La historia, en el sentido narrativo, es el principio de lo que al-Ŷābrī denomina un "bloque histórico" (kutla tārījiyya) que cuente con todos los actores ideológicos y sociales (al-Ŷābrī, 2004: 162), de forma que a partir de dicho análisis y mediante una interpretación conjunta, pueda afrontarse la tarea de un cambio social colectivo. No es ajeno a este concepto de "kutla" el bloque político que se conforma en Marruecos como actor proactivo de un cambio democrático en el marco de la alternancia política en los años noventa del siglo XX (Parejo Fernández, 2005). Es interesante observar la perspicacia de este análisis sólo unos años antes del comienzo de las revueltas árabes de 2011, en la que se observará la construcción conjunta de un discurso basado en este mismo análisis. En él, la "democracia social" se establece como una necesidad histórica propiciada por el cambio social.

Para al-Ŷābrī este concepto de "democracia social" (al-dīmuqrāțiyya al-iŷtimā'iyya) sintetiza la relación entre la sociedad y el estado y se comporta como un concepto generador de discurso de primer orden. No cabe duda de que el concepto de "democracia" ha configurado el discurso político árabe a lo largo del siglo XX y XXI; para al-Ŷābrī el concepto en sí carece de sentido, de significado real y de utilidad, según afirma en su obra al-Dīmuqrāțiyya wa-ḥuqūq al-insān (Democracia y derechos humanos), en tanto dicha democracia no esté basada en la libertad como valor supremo, distinguiéndola así de la "libertad" como mero concepto legitimador discursivo del despotismo (al-Ŷābrī, 1997:18). En este plano moral, sin la libertad no puede existir la justicia. La "democracia política" (al-dīmuqrāțiyya al-siyāsiyya) debe garantizar la estructura suficiente para ejercer la libertad y la igualdad, pero es la democracia social la que, partiendo de la autoconciencia social y cultural (relectura del turāts) permite a la democracia política lograr sus objetivos. Para alYaābrī es importante destacar que la narrativa democrática árabe debe construirse con un discurso propio que parta de dicha autoconciencia también en el plano histórico, de la conciencia del individuo contemporáneo como ciudadano sujeto de derechos (al-Ŷābrī, 1997: 131). La tarea histórica que al-Ŷābrī defiende es la lucha colectiva por la democracia social como garantía metodológica para conseguir la unidad con los objetivos de la democracia política, principalmente la igualdad, la libertad y la justicia, en la que el ciudadano puede finalmente ejercer y disfrutar los derechos que les son propios. En esta lucha, al-Ŷābrī, a pesar de todo, sitúa a los partidos políticos junto con la sociedad civil como agentes de transformación social, en un contexto en el que no era concebible otro tipo de organización ciudadana que pudiera sustituir el papel histórico de estos actores. 
La necesidad histórica de la democracia se plantea en todo caso desde la concepción de ésta como un fundamento ( $m a b d a^{\prime}$ ) y como un marco que permite a las personas ejercer efectivamente sus derechos de ciudadanía (al-Ŷābrī, 1997:132). Así entendida, la democracia es una necesidad en términos absolutos, marroquí en primer término y árabe en segundo, pero también global, puesto que para él no existe alternativa a este movimiento histórico global hacia la democracia (laysa gayr al-dīmuqrāțiyya badīl tārijīi) (al-Ŷābrī, 1997:136). En este sentido, es fácil leer la narrativa democrática de al-Ŷābrī desde el contexto histórico de las revueltas árabes de 2011 y su influencia internacional, así como observar la cercanía del discurso de Muhammad 'Ābid al-Ŷābrī con las propuestas y las reivindicaciones de los actores democratizadores en los últimos veinte años. Por tanto, la narrativa democrática en al-Ŷābrī se caracteriza por una clara dialéctica histórica y su discurso se centra en la sociedad como sujeto colectivo de reflexión y acción colectiva.

\section{Conclusiones}

Como se ha visto, a lo largo de este trabajo se han recogido los principales elementos narrativos del discurso democrático en Marruecos a través del discurso de tres de los intelectuales más influyentes en el ámbito social de las últimas décadas: Kamāl 'Abd al-Lațîf, Ṭāhā 'Abd al-Raḥmān y Muḥammad 'Ābid al-Ŷābrī. A través del análisis narrativo del discurso textual de estos tres autores se ha podido deconstruir su narrativa en dos elementos principales: la historia, enmarcada en el desarrollo socio-histórico y político de espacios de democratización en Marruecos a lo largo de las últimas dos décadas; y el discurso, circunscrito al modo de narrar la historia desde el ámbito ideológico como representación social subjetiva. Hecho esto, se han observado los principales conceptos generadores de discurso (explícitos) y los principales conceptos generadores de significado (implícitos) en cada uno de estos discursos, estableciendo con ello un concepto clave que identifica el discurso y construye, desde la subjetividad, una narrativa concreta. Conforme a ello, los resultados del análisis estarían comprendidos en la siguiente tabla:

Figura 1: Elementos narrativos del discurso democrático

\begin{tabular}{|c|c|c|c|c|c|}
\hline AUTOR & HISTORIA & DISCURSO & $\begin{array}{c}\text { GENERADORE } \\
\text { S DISCURSO }\end{array}$ & $\begin{array}{l}\text { GENERADORES } \\
\text { SIGNIFICADO }\end{array}$ & NARRATIVA \\
\hline $\begin{array}{l}\text { K. ‘ABD } \\
\text { AL-LAṬīF }\end{array}$ & $\begin{array}{c}\text { Post- } \\
\text { colonialismo }\end{array}$ & $\begin{array}{l}\text { Modernidad } \\
\text { política }\end{array}$ & $\begin{array}{c}\text { Historia } \\
\text { Conciencia } \\
\text { Cambio } \\
\text { cultural } \\
\end{array}$ & $\begin{array}{l}\text { Colonialismo } \\
\text { Dependencia }\end{array}$ & Política \\
\hline $\begin{array}{l}\text { T. ‘ABD AL- } \\
\text { RAḤMĀNN }\end{array}$ & Globalización & $\begin{array}{l}\text { Modernidad } \\
\text { ética }\end{array}$ & $\begin{array}{l}\text { Ética / Moral } \\
\text { Modernidad } \\
\text { Islam }\end{array}$ & $\begin{array}{l}\text { Materialismo } \\
\text { Injusticia }\end{array}$ & Ética \\
\hline $\begin{array}{l}\text { M. ‘'̄. AL- } \\
\hat{\text { ŶĀBRĪ }}\end{array}$ & Alternancia & $\begin{array}{c}\text { Democracia } \\
\text { social }\end{array}$ & $\begin{array}{c}\text { Democracia } \\
\text { Sociedad civil } \\
\text { Turāă } \\
\text { Nahḍa }\end{array}$ & Autoritarismo & Social \\
\hline
\end{tabular}

Fuente: elaboración propia 
Se observan tres narrativas alternativas centradas, en cada caso, en tres ámbitos complementarios: la política, la ética y la sociedad. Las tres alternativas se construyen con un discurso que identifica la modernidad con el desarrollo de cada uno de estos tres ámbitos. La modernidad es política en el discurso de Kamāl 'Abd al-Lațîf cuando es una modernidad consciente de ser postcolonial y, por tanto, consciente de la colonialidad histórica. Su discurso se genera en torno a conceptos que ponen de manifiesto este "ser post-colonial" de manera consciente, adquiriendo significado cuando se contrapone al hecho colonial y a la dependencia, tanto histórica como cultural que impide llegar a la modernidad plena. En el caso de Ṭāhā 'Abd al-Raḥmān la modernidad es ética en cuanto responde, mediante un discurso que identifica la moral islámica con el humanismo ético, al materialismo salvaje y a la injusticia de la globalización desde valores y presupuestos culturales propios. Finalmente, en el caso de Muḥammad 'Ābid al-Ŷābrī, la modernidad, en términos políticos, se corresponde con una democracia social basada en la necesidad de establecer la igualdad y la libertad como principios de una sociedad moderna y justa. En el camino de la alternancia y la democratización que responde dialécticamente al autoritarismo histórico, la relectura racional del turāt permite encontrar elementos intelectuales de liberación y elaborar un proyecto de resurgimiento (nahd̦a) político, social y cultural colectivo. Las tres narrativas, por tanto, son alternativas pero complementarias, esbozando un amplio discurso democrático que responde dialécticamente a la realidad histórica que lo contextualiza, y devolviéndolo, en forma de propuesta intelectual, a la sociedad que la protagoniza.

\section{Bibliografía}

'ABD AL-LAṬīF, Kamāl (2016): Al-'Arab fi zamān al-murāŷa'āt al-kubrà: muhāwalāt fĩ ta'aqqul taḥawwulāt al-rāhin al-'arabī, Doha, al-Markaz al-'arabī li-l-abḥāt wa-dirāsat al-siyāsāt.

'ABD AL-LAṬīF, Kamāl (1997): Al-'Arab wa-l-ḥadāta al-siyāsiyya, Beirut, Dār al-Fikr.

'ABD AL-LAṬīF, Kamāl y 'ĀRIF, 'A. (2001): Iškāliyyāt al-jițāb al-'arabī l-mu'āṣir, Damasco, Dār al-fikr. 'ABD AL-RAHMĀN, Țāhā (2006): Rūh al-hadāta: al-madjal ilà ta'sīs al-hadāta al-islāmiyya, Casablanca, al-Markaz al-taqāfī l-'arabī.

ABI-MERSHED, Osama (ed.)(2018): Social currents in North Africa. Culture and Governance after the Arab Spring, London, Hurst

AHLUWALIA, Pal (2010): Out of Africa. Post-structuralism's colonial roots. London: Routledge.

AKSIKAS, Jaafar (2009): Arab modernities. Islamism, Nationalism, and Liberalism in the PostColonial Arab World, New York, Peter Lang.

ALFAISAL, Haifa S. (2011): "Indigenous epistemology and the Decolonization of Postcolonialism", Studies in Social and Political Thought, 19 (Summer 2011), pp. 24-40.

AYALON, Ami (1987): Language and change in the Arab Middle East. The evolution of Modern Political Discourse, New York, Oxford, Oxford University Press.

BELQAZ̄̄Z, 'Abd al-Ilāh (2000): Nihāyat al-dā'iyya. Al-Mumkin wa-l-mumtani' fī adwār almutaqqafinn, Casablanca, Al-Markaz al-țaqāfi l-'arabī.

BENMESSAOUD TREDANO, Abdelmoughit (2000): L'Alternance. Du consensus aux urnes, Rabat, El Maarif El Jadida. 
BERRADA, El Mehdi e IRAQI, Fahd: "Boycott au Maroc: un "Hirak " numérique", Jeune Afrique (12/06/2018), disponible en http://www.jeuneafrique.com/mag/564706/economie/boycott-aumaroc-un-hirak-numerique/ [consulta: 13 de junio de 2018].

BOUKHARS, Anouar (2011): Politics in Morocco. Executive monarchy and enlightened authoritarianism, London, Routledge.

BUEHLER, Matt (2018): "Labor protest in Morocco: strikes, concessions, and the Arab Spring", en ABI MERSHED, Osama (ed.): Social currents in North Africa. Culture and Governance after the Arab Spring, London, Hurst, pp. 51-72.

CAVATORTA, Francesco y MERONE, Fabio (2018): "Islamist parties and transformation in Tunisia and Morocco" en ABI MERSHED, Osama (ed.): Social currents in North Africa. Culture and Governance after the Arab Spring, London, Hurst, pp. 11-30.

CHAKRAVORTY SPIVAK, Gita (2010): Crítica de la razón poscolonial: Hacia una crítica del presente evanescente, Madrid, Akal.

CHATMAN, Seymour (1978): Story and discourse. Narrative structure in fiction and film, Ithaca, Cornell University. Trad. Española de María Jesús Fernández Prieto. CHATMAN, Seymour (2014): Historia y discurso. La estructura narrativa en la novela y en el cine, Barcelona, RBA.

DABASHI, Hamid (2012): The Arab Spring: The End of Postcolonialism, New York, Zed Books.

DABASHI, Hamid (2009): Post-Orientalism: Knowledge and Power in a Time of Terror, Piscataway, Transaction.

DARIF, Mohamed (2014): “Morocco, a reformist monarchy?", en LARÉMONT, René (ed.): Revolution, Revolt and Reform in North Africa. The Arab Spring and beyond, London, Routledge, pp. 105-124. DOI: https://doi.org/10.1080/21520844.2012.675544

DESRUES, Thierry y HERNANDO DE LARRAMENDI, Miguel (coords.) (2011): Mohamed VI. Política y cambio social en Marruecos. Las claves del proceso de transformación que se opera en el país vecino, Córdoba, Almuzara.

DESRUES, Thierry y MOYANO, Eduardo (2000): "Cambio social y transición política en Marruecos", Revista de Estudios Políticos (Nueva Época), 109, pp. 265-284. Disponible en https://dialnet.unirioja.es/servlet/articulo?codigo=27615 [consulta: 12 de julio de 2018]

FORNARI, Emanuela (2017): Líneas de frontera: filosofía y postcolonialismo, Barcelona, Gedisa.

GALLĀB, 'Abd al-Karīm (1993): Fì I-fikr al-siyāsī, Casablanca, Al-Šarika al-magribiyya li-l-țabā'a wa-Inašr.

GALLĀB, 'Abd al-Karīm (1999): Lā mafhūm li-l-țaqāfa, Rabat, al-Ma'arifa.

GENETTE, Gérard (1983): Nouveau discours du récit, Paris, Seuil.

HALLIDAY, Fred y ALAVI, Hamza (eds.) (1988): State and Ideology in the Middle East and Pakistan, London, Macmillan.

HUSSEIN, Abdirahman A. (2002): Edward Said: Criticism and society, London, Verso.

JABIRI, Vivienne (2013): The Postcolonial subject. Claiming politics/governing others in late modernity, London, Routledge.

KASSAB, Elisabeth S. (2013): "The Arab quest for freedom and dignity: have Arab Thinkers been part of it?", Middle East - Topics and Arguments, 1, pp. 26-34. DOI: https://doi.org/10.17192/meta.2013.1.1038

KHOURY, Paul (2012): Pensée arabe contemporaine. Tradition et modernité, Paris, L'Harmattan.

LAROUI, Abdallah (1970): Al-'îdiyūlūŷiyā l-'arabiyya al-mu'āsira, Beirut, Dār al-haqīqa.

LOUDIY, Fadoua (2014): Transitional justice and Human Rights in Morocco. Negotiating the Years of Lead, London, Routledge. DOI: 10.4324/9781315856063

MACÍAS AMORETTI, Juan A. y ARIGITA MAZA, Elena (eds.) (2015) : (Dis)continuidades árabes. Discursos e imaginarios en un contexto de cambios, Granada, Comares. 
MACÍAS AMORETTI, Juan A. (2015) : “¿Vamos o viene? La democracia como texto filosófico y discurso ideológico en Marruecos", en MACÍAS AMORETTI, Juan A. y ARIGITA MAZA, Elena (eds.): (Dis)continuidades árabes. Discursos e imaginarios en un contexto de cambios, Granada, Comares, pp. 43-64.

MAGHRAOUI, Driss (2013): "Constitutional reforms in Morocco: between consensus and subaltern politics", en JOFFE, G. (ed.): North Africa's Arab Spring, London, Routledge, pp. 175-195. DOI: https://doi.org/10.1080/13629387.2011.630879

MEMMI, Albert (1973): Portrait du colonisé, précédé du portrait du colonisateur, Prol. Jean-Paul Sartre, Paris, Payot.

PAREJO FERNÁNDEZ, Mạ Angustias (2005): "Islas de democracia en un mar de transiciones en Marruecos", Hesperia. Culturas del Mediterráneo, 2, pp. 77-102.

PAREJO FERNÁNDEZ, Ma Angustias (2010): “Liberalización política y redefinición de la oposición: la "Kutla" y la reforma constitucional en Marruecos (1992-2006)", Miscelánea de Estudios Árabes y Hebraicos-Sección Árabe-Islam, 59, pp. 91-114, disponible en http://www.meaharabe.com/index.php/meaharabe/article/view/59 [consulta: 12 de julio de 2018].

PÉREZ BELTRÁN, Carmelo (2016): “La sociedad civil en el Magreb : ¿elemento vertebrador de la democracia ?", en VELASCO DE CASTRO, Rocío et. al. (eds): Religión, derecho y sociedad en la organización del estado, Valladolid, Veritas/Omnia Mutandur.

PÉREZ BELTRÁN, Carmelo (ed.) (2006): Sociedad civil, derechos humanos y democracia en Marruecos, Granada, Universidad de Granada.

PÉREZ BELTRÁN, Carmelo y MACIAS AMORETTI, Juan A. (2017): “La construcción histórica de la hegemonía ideológica del PJD en Marruecos: el caso de la marcha islámica de 2000 y el debate sobre las mujeres", Revista de Estudios Internacionales Mediterráneos, 22, pp. 1-34. DOI: http://dx.doi.org/10.15366/reim2017.22.001

SATER, James N. (2007): Civil Society and Political Change in Morocco, London, Routledge.

TODOROV, Tzvetan (1978): Symbolisme et interprétation, Paris, Seuil.

VAN DIJK, Teun A. (2011): Ideología y discurso, Barcelona, Ariel

VAN DIJK, Teun A. (2016): “Análisis Crítico del Discurso", Revista Austral de Ciencias Sociales 30, pp. 203-222, disponible en http://revistas.uach.cl/index.php/racs/article/view/871 [consulta 28 de noviembre de 2018].

VAIREL, Frédéric (2014): Politique et mouvements sociaux au Maroc. La révolution désamorcée ?, Paris, Presses de Sciences Po.

ŶĀBRĪ, Muḥammad 'Ābid al- (1994): Al-Dīmuqrāțyya wa-ḥuqūq al-insān, Beirut, Markaz dirāsāt alwaḥda al-'arabiyya.

ŶĀBRĪ, Muḥammad 'Ābid al- (1999): “L'ambition du gouvernement Youssoufi: une société démocratique. Entretien avec Mohammed Abed al-Jabri”, par Oussama Gaber et Jean-Christophe Ploquin, Confluences Méditerranée, 31, pp. 133-144.

ŶABRĪ, Muḥammad 'Ābid al- (2000): Al-Mašrū' al-nahd̦awī l-'arabī. Murāŷa'a naqdiyya, 2a ed, Beirut, Markaz dirāsāt al-waḥda al-'arabiyya.

ŶABRĪ, Muḥammad 'Ābid al- (2005): Al-Muŷtama' al-madanī. Tațawwur al-nujba al-muțaqqafa almagribiyya, Casablanca, Dār al-Našr.

ŶĀBRĪ, Muḥammad 'Ābid al- (2004): Wiŷhat naẓar: naḥwa i'āda binā' qad̦āyā l-fikr al-'arabī lmu'āșir, 3ạ ed, Beirut, Markaz dirāsāt al-waḥda al-'arabiyya.

YĀSĪN, Sayyid (1998): Al-zaman al-'arabī wa-I-mustaqbal al-'ālam, Cairo, Dār al-mustaqbal al-'arabī. 